\title{
Pragmatic randomised trial of a smartphone app (NRT2Quit) to improve effectiveness of nicotine replacement therapy in a quit attempt by improving medication adherence: results of a prematurely terminated study
}

\author{
Aleksandra Herbec ${ }^{1,2,3^{*}}$ D, Jamie Brown ${ }^{2}$, Lion Shahab ${ }^{2}$, Robert West ${ }^{2}$ and Tobias Raupach ${ }^{3,4,5}$
}

\begin{abstract}
Background: Nicotine replacement therapy (NRT) bought over the counter (OTC) appears to be largely ineffective for smoking cessation, which may be partially explained by poor adherence. We developed and evaluated the NRT2Quit smartphone app (for iOS) designed to improve quit attempts with OTC NRT by improving adherence to the medications.

Methods: This study was a pragmatic double-blind randomised controlled trial with remote recruitment through leaflets distributed to over 300 UK-based community pharmacies. The study recruited adult daily smokers $(\geq 10$ cigarettes per day) who bought NRT, wanted to quit smoking, downloaded NTR2Quit and completed the registration process within the app. Participants were automatically randomly assigned within the app to the intervention (full) version of NRT2Quit or to its control (minimal) versions. The primary outcome was biochemically verified 4-week abstinence assessed at 8-week follow-up using Russell Standard criteria and intention to treat. Bayes factors were calculated for the cessation outcome. Secondary outcomes were self-reported abstinence, NRT use, app use and satisfaction with the app.

Results: The study under-recruited. Only 41 participants (3.5\% of the target sample) were randomly assigned to NRT2Quit $(n=16)$ or the control $(n=25)$ app versions between March 2015 and September 2016. The follow-up rate was 51.2\%. The intervention participants had numerically higher biochemically verified quit rates $(25.0 \%$ versus $8.0 \%, P=0.19$, odds ratio $=3.83,0.61-24.02$ ). The calculated Bayes factor, 1.92 , showed that the data were insensitive to test for the hypothesis that the intervention app version aided cessation. The intervention participants had higher median logins ( 2.5 versus 0 , $P=0.01)$ and were more likely to use NRT at follow-up $(100.0 \%$ versus $28.6 \%, P=0.03)$ and recommend NRT2Quit to others $(100.0 \%$ versus $28.6 \%, P=0.01)$.
\end{abstract}

Conclusions: Despite very low recruitment, there was preliminary but inconclusive evidence that NRT2Quit may improve short-term abstinence and adherence among smokers using NRT. Well-powered studies on NRT2Quit are needed, but different recruitment methods will be required to engage smokers through community pharmacies or other channels.

Trial registration: ISRCTN ISRCTN33423896, prospectively registered on 22 March 2015.

Keywords: Smoking cessation, Medication adherence, Nicotine replacement therapy, Smartphone application

\footnotetext{
* Correspondence: a.herbec@ucl.ac.uk

${ }^{1}$ Clinical, Educational and Health Psychology, University College London, 1-19

Torrington Place, WC1E 6BT, London, UK

${ }^{2}$ Behavioural Science and Health, University College London, 1-19 Torrington

Place, WC1E 6BT, London, UK

Full list of author information is available at the end of the article
}

(c) The Author(s). 2019 Open Access This article is distributed under the terms of the Creative Commons Attribution 4.0 International License (http://creativecommons.org/licenses/by/4.0/), which permits unrestricted use, distribution, and reproduction in any medium, provided you give appropriate credit to the original author(s) and the source, provide a link to the Creative Commons license, and indicate if changes were made. The Creative Commons Public Domain Dedication waiver (http://creativecommons.org/publicdomain/zero/1.0/) applies to the data made available in this article, unless otherwise stated. 


\section{Background}

High-quality evidence from randomised trials shows that nicotine replacement therapy (NRT) is effective when provided with at least some professional support [56]. However, large-scale surveys and prospective studies have found that smokers who buy NRT over the counter (OTC NRT) and do not receive any processional support have quit rates that are similar to, or lower than, those of smokers who quit unaided, even when a range of potential confounding variables are adjusted for [33-35]. One explanation for the discrepancy in effectiveness between NRT in trials and NRT bought OTC is low adherence $[3,5,15,19,31,48,55]$. There is some research to suggest that better adherence is associated with better cessation outcomes [18, 40, 48, 53]. Smartphone applications (apps) could improve NRT adherence and thus success rates in smokers, especially among those using OTC NRT [36, 47, 49].

Smartphone apps have become an increasingly popular medium to deliver support for a range of health conditions [28] and for medication use [2, 45, 52]. Apps have also been developed to promote smoking cessation, but many of these have been shown to offer only limited support with quitting, and as yet none has been developed specifically to promote NRT adherence [1, 2, 29, 59].

We developed an app for iOS phones, called NRT2Quit, that aimed to support smokers who are using NRT to quit smoking, and the focus was on those who purchase OTC NRT. NRT2Quit was developed following the methods outlined in the Behaviour Change Wheel [41] and was informed by the COM-B model (Capability, Opportunity, Behaviour $[32,43])$ and Theoretical Domains Framework (version 2 [4]) as well as the framework of intentional and non-intentional non-adherence [38], the Necessity Concerns Framework [30], the Compliance and Persistence Framework [17], PRIME Theory of Motivation [62] and best clinical practice identified through consultations with the UK's National Centre for Smoking Cessation and Training.

NRT2Quit was designed to deliver easily accessible general advice on quitting as well as detailed guidelines about NRT, including instructions on medication use, information addressing intentional and modifiable reasons for poor adherence, such as limited knowledge and concerns $[30,46]$, and features for monitoring and feedback on NRT use. NRT2Quit delivered 25 behaviour change techniques (BCTs) directly addressing NRT use and 27 BCTs addressing quitting in general [42]; in comparison, $12 \mathrm{BCTs}$ on average were found in apps supporting adherence to other medications [45]. It was expected that NRT2Quit would aid cessation by offering advice, reassurance and encouragement to use NRT according to best clinical practice during a quit attempt.
Choosing the right control conditions for the evaluation of apps remains challenging [44]. It was decided that the most appropriate and realistic comparison to NRT2Quit would be a version of the app that offered a minimum credible intervention [44] by being similar to the intervention in many respects (e.g., the registration flow and design) but providing only limited support. There were two main reasons for this approach. First, from an ethical point of view, it was important to offer at least brief advice to smokers who were interested in using an app to help them quit. Second, the similarities between the two arms increase credibility of the control app, potentially minimising the seeking of alternative apps or support, which likely would have increased attrition from the trial and reduced power to detect an effect [44].

Finally, given that the effectiveness of OTC NRT is low $[34,35]$, it was important to evaluate NRT2Quit in an OTC setting and with no involvement of the researchers, pharmacists or other healthcare professionals (HCPs). It was judged that promoting the study among community pharmacies would offer the best chance to reach smokers who have just purchased OTC NRT and who might not have received additional support with NRT use.

\section{Aims}

The main aim of this pragmatic trial was to evaluate the short-term effectiveness of NRT2Quit. We hypothesised that, in comparison with the control app version, the intervention app would lead to increases in (1) biochemically verified 4-week-long abstinence assessed at 8-week follow-up, (2) self-reported use of NRT, (3) app usage, and (4) satisfaction with the app.

\section{Materials and methods \\ Design}

The study was a pragmatic remote two-arm parallel double-blind randomised controlled trial in the UK, and 1:1 automatic randomisation to the intervention and control versions was based on a random numbers function embedded within the registration process within the app, and the study had an 8-week follow-up. The study received ethical approval from the University College London Research Ethics Committee (ID: 5398/001) and was prospectively registered (ISRCTN33423896). The reporting follows Consolidated Standards of Reporting Trials (CONSORT) [51] (Additional file 1) and Template for Intervention Description and Replication (TIDieR) guidelines [25]. Two changes to the protocol were made after the trial began: 7-month follow-up was suspended, and participants using NRT by prescription were included (see Additional file 2 for details). Also, owing to very slow recruitment, the trial was terminated after 18 months. 


\section{Participants}

\section{Participant recruitment}

Recruitment was through self-identification and self-selection and was conducted remotely with no contact with the researcher [24]. The recruitment campaign lasted between 23 March 2015 and 15 September 2016. Recruitment materials were delivered to around 300 UK community pharmacies, mostly through their central managerial offices, with instructions to display and distribute them among smokers who purchase NRT (see Additional file 3 for recruitment materials). The materials directed potential participants to the study website with a detailed study information sheet, information about data processing, end user licence agreement, and links to download the app for free (www.nrt2quit.co.uk). The app could also be found through online searches and on iTunes.

\section{Recruitment via community pharmacies}

The majority $(n=250)$ of the pharmacies belonged to one large pharmacy chain and were identified through the central managerial office, which was supportive of the study. Fifty more pharmacies were recruited from other major pharmacy chains by communicating with their communications teams and by directly approaching several independent pharmacies. However, no training or direct communication between the researchers and the pharmacy staff was planned (to limit staff burden and to ensure that the context of recruitment of smokers remained as ecological as possible) or possible.

The study promotion could take place only outside of the busy periods, such as Christmas and New Year's. Only leaflets, rather than larger posters, could be distributed in the participating pharmacies. The leaflet delivery was preceded by internal email communication and accompanied by a printed letter for the head pharmacists, instructing them to place the leaflets near the counters and NRT displays and to provide leaflets to customers purchasing OTC NRT. No professional company was involved in developing the recruitment campaign, and it was not possible to trial the recruitment materials or procedures. Some of the pharmacies in London were visited by the first author to identify ways of improving recruitment, but no further changes to recruitment were possible.

\section{Eligibility criteria}

Only iPhone users (with iOS 8+) could participate. Eligibility for the trial was assessed on the basis of the information provided during registration via the app: (a) UK-based; (b) age of at least 18 years; (c) daily smoking of at least 10 cigarettes per day; (d) use at least one NRT product; (e) downloaded the app to quit; (f) completed registration process, including providing plausible and complete contact details (these were assessed manually by the researcher); and (g) provided consent to participate that also implied no contraindications for NRT use.

\section{Sample size}

The target sample size was calculated a priori to be 1186 participants (with alpha $=0.05$, two-tailed) to have $80 \%$ power to detect an expected effect size of odds ratio (OR) of 1.7, translating to 5\% difference in self-reported abstinence rates at 8 -week follow-up ( $8 \%$ in the control and $13 \%$ in the intervention). The expected cessation rates for intention to treat were low as it was expected that attrition from the study would be as high as $50 \%$ from each group [23]. The expected effects were small but potentially cost-effective [61].

\section{NRT2Quit platform and intervention and control arms}

NRT2Quit intervention and control app versions were delivered through a single NRT2Quit app platform that could be used offline except for changing the quit date or NRT use to ensure data were synchronised with the server. Both versions of NRT2Quit were developed to be automated and standalone interventions. The advice offered was tailored to the type of NRT product used and the quit date (control and intervention) and to dependence level (intervention only, see 2.3.2). The support was offered for up to 2 weeks before the quit date and 8 weeks post-quit date. Detailed information about the NRT2Quit functionality, the different BCTs delivered within the app (25 BCTs targeting adherence to NRT and 27 targeting smoking cessation in general), screenshots, and user journeys of the intervention and control is provided in Additional file 4. The app was not modified during the trial.

\section{NRT2Quit - Control (minimal) version}

The control version of the app provided only minimal support with quitting and NRT use: (1) setting of a quit date in the next 2 weeks, (2) very brief advice on the use of selected NRT, (3) brief advice on quitting and managing nicotine withdrawal, (4) progress monitoring (days to and since the quit date), (5) a calendar that displays the quit date and the 8-week questionnaire. It also included (6) brief information about the study and the app. Users could (7) change the quit date and the NRT used.

\section{NRT2Quit - Intervention (full) version}

The intervention version of NRT2Quit offered the same support as the control version and in addition provided (1) more comprehensive information about NRT in general and about each product (e.g., detailed instructions on use and short articles about key misconceptions such as overdosing), (2) an interactive dashboard for monitoring and feedback on NRT use, (3) daily diary on smoking and 
NRT use followed by tailored feedback, (4) more detailed advice on quitting, (5) daily tips, (6) additional information about the study team and study rationale, and (7) daily reminders to engage with the app. Feedback and advice on NRT use were minimally tailored to dependence levels (heavy smokers were all those who were smoking 11 to 19 cigarettes per day and smoking the first cigarette within 5 min since waking or all those smoking at least 20 cigarettes per day; moderate smokers consisted of everyone else). The app was designed to encourage daily use (e.g., through app reminders and new daily tips). However, in anticipation of high attrition from the app [23] and given the different preferences for usage of digital interventions among smokers [26], the core content and BCTs were delivered immediately following the registration.

\section{Procedures}

After downloading the app, participants were guided through a tunnelled registration process that included a summary of study information sheet and links to the study website with detailed information, provided informed consent and contact details, completed baseline assessment, entered data on the NRT purchased, and set their quit date (Additional file 5). After registering, participants were automatically randomly assigned to the intervention or control versions of the app and were assigned a unique ID. Participants received an email confirming registration with a link to the study website and contact details to the researchers. Duplicate registrations were excluded following a manual check.

The follow-up took place 8 weeks after the registration (18 May 2015 to 22 November 2016) through an online survey as opposed to within the app (in anticipation that participants would delete the app or switch off notifications). The links to the survey were distributed through emails (up to three reminders) that were personalized [11]. Participants failing to complete the survey were contacted over the phone (up to three calls) to assess smoking status only (a longer survey was judged to be not feasible over the phone). Participants self-reporting prolonged abstinence were posted a saliva kit with instructions, a $£ 20$ high street gift voucher as reimbursement, and a freepost envelope addressed to the laboratory and were asked to post the samples as soon as possible [11].

Owing to slow recruitment, it was decided in early August 2016 to prepare for termination of the trial. Bayes factors were calculated on the primary outcome on 18 August 2016 (after 39 eligible participants were recruited), but no hypothesis testing or other analyses were performed. Before NRT2Quit was removed from iTunes on 15 September (the current app users could still access it), two additional participants meeting eligibility criteria joined the study and were included in the analyses reported here. All study procedures, including the follow-up for all participants, were conducted blind to study arm allocation.

\section{Measurements \\ Baseline assessment}

The baseline questionnaire assessed socio-demographic characteristics (age, gender, and having education after 16 years of age versus not), smoking and quitting history (items from the Heaviness of Smoking Index [22], when the last quit attempt was made, past use of cessation aids) and reasons for joining the study (to quit smoking/ other). Participants also provided information about the NRT type purchased (NRT patch/fast-acting NRT/combination), how they obtained NRT (OTC/on prescription/both) and whether they received any support with NRT use from HCPs (yes/no).

\section{Primary outcome}

The primary outcome was self-reported 4-week prolonged abstinence assessed at 8-week follow-up and was verified by saliva cotinine levels of less than $15 \mathrm{ng} / \mathrm{mL}$ [64] or, among participants reporting using NRT or ecigarettes, anabasine levels of less than $1 \mathrm{ng} / \mathrm{mL}[7,11]$. The pre-registered salivary anabasine cutoff value was based on discussions with the processing lab and the information available at the time of trial set-up (20112014). However, as the lab has conducted more studies since, it now recommends a lower cutoff value for salivary anabasine of less than $0.2 \mathrm{ng} / \mathrm{mL}$. Results for the lower cutoff are reported in the footnote of Table 2. Participants lost to follow-up were assumed to have resumed smoking, as per intention-to-treat (ITT) principle.

\section{Secondary outcomes}

Secondary outcomes were (1) the follow-up parameters: follow-up rate, the re-contact channel (survey/phone), and proportion of saliva samples returned. The online survey at 8-week follow-up assessed: (2) total number of cigarettes smoked in the past 4 weeks (none/ $<5 / \geq 5$ ); (3) adherence to NRT: (i) use of NRT on the follow-up day (yes/no), (ii) weeks NRT was used $(<5 / \geq 5$ weeks), and (iii) number of days in those weeks NRT was used (every day/not every day); (4) use of other cessation support such as other medications, behavioural support, or selfhelp support (yes/no); (5) satisfaction: how helpful was NRT2Quit app for (i) quitting smoking and (ii) using NRT $(1=$ not at all and $5=$ extremely helpful), (iii) whether the participant would recommend the app to others wanting to quit (yes/no). Additionally, (6) data on app usage: (i) number of logins and (ii) number of days users logged in on. Owing to the structure of the app 
database, data on time spent using the app or on accessing individual app features were not saved.

\section{Data analysis}

The primary outcome was analysed by using Fisher's exact test. Additionally, unadjusted logistic regressions were conducted for the dichotomised cessation outcomes, and ORs and 95\% confidence intervals were calculated. In exploratory sensitivity analyses, participants who reporting using only NRT by prescription $(n=14)$ or for whom that data was missing $(n=3)$ were excluded. All other analyses were pre-planned. For smoking outcomes, participants with missing data were assumed to be smoking.

Bayes factors were calculated for the smoking outcomes as they can distinguish between the likelihood of both the null and alternative hypotheses and assess whether the data provide an insensitive test of the hypotheses [12, 20, 21, 63]. Bayes factors were calculated by using an online calculator that is available for free at http://www.lifesci.sussex.ac.uk/ home/Zoltan_Dienes/inference/Bayes.htm. We used a uniform $\mathrm{H} 1$ distribution with a possible expected effect size between $\mathrm{OR}=1$ and $\mathrm{OR}=3$ versus an $\mathrm{H} 0$ of $\mathrm{OR}=1$. In sensitivity analyses, we used a conservative $\mathrm{H} 1$ with a halfnormal distribution with the mean of the $\log$ OR of 0 and the standard deviation corresponding to expected effect sizes of $\mathrm{OR}=1.2, \mathrm{OR}=1.7$, and $\mathrm{OR}=2.5[50,63]$. This distribution means that plausible values have been represented between zero and twice the effect size, and smaller values are more likely.

Descriptive statistics are presented for baseline and all secondary outcomes. Categorical variables were compared by using Fisher's exact test, and chi-squared test and linear-by-linear association for ordered categories, and continuous data using independent $t$ test or MannWhitney $U$ test for data that were not normally distributed. Data on app usage were not normally distributed, but both medians (interquartile ranges) and means (standard deviations) are reported to enable comparison with other studies. All tests were two-sided and alpha was set to $5 \%$.

\section{Results}

\section{Participants}

Owing to very slow recruitment, the trial was terminated and the analysis involved only 41 participants, who met eligibility criteria for the study, of which 16 (39.0\%) were randomly assigned to the intervention app. Figure 1 (based on the CONSORT flow diagram) shows the flow of participants, and Table 1 presents baseline characteristics. A significant minority came across the app through an online search or other channels. About half of participants were female, had education after 16 years of age, and made an attempt to quit in the past 12 months. Almost all participants had used some cessation assistance before; NRT (41.5\%) and e-cigarettes (24.4\%) were the most common. At baseline, $43.9 \%$ of participants reported they were using a fast-acting NRT product on its own and $26.8 \%$ were using combined NRT. A quarter of participants obtained advice from HCPs on NRT use.

\section{Follow-up}

At 8-week follow-up, 51.2\% of participants were successfully contacted (43.8\% among intervention and 56.0\% among control; Table 3). The online follow-up survey that assessed additional secondary outcomes was completed by $12(29.3 \%)$ participants. The rates were similar across study arms.

\section{Cessation outcomes}

Table 2 presents cessation outcomes assessed at 8-week follow-up. In the ITT analysis, abstinence was biochemically verified for $14.6 \%$ of trial participants $(25.0 \%$ among intervention and $8.0 \%$ among control; $P=0.19$ ). The results changed only minimally when the cutoff of less than $0.2 \mathrm{ng} / \mathrm{mL}$ for salivary anabasine was used. Selfreported abstinence was reported by $17.1 \%$ of participants $(25.0 \%$ among intervention versus $12.0 \%$ among control; $P=0.40)$. The Bayes factors $(B=1.92)$ calculated for biochemically verified and self-reported abstinence suggested that the data were insensitive to distinguishing between the null and experimental hypotheses. The results did not change when the analysis was limited to participants who bought at least one of their NRTs OTC (not reported here).

\section{NRT use}

Among participants who completed the online survey $(n=12)$, adherence rates were relatively high, and the differences between study arms were not statistically significant except for having used NRT on the survey day $(100 \%$ in the intervention versus $28.6 \%$ in the control arm; $P=0.03$; see Table 3 for details).

\section{App usage}

App usage (see Table 3 for details) was low and positively skewed in both conditions, but there was an indication that the intervention participants engaged more (e.g., median number of logins: 2.5 versus $0 ; P=0.01$ ). This is an underestimation, however, as offline use might not have been saved on servers (e.g., if the participants used the app offline for a period but then permanently disengaged with the app).

\section{Satisfaction}

Among the 12 participants who completed the survey (Table 3), the intervention participants gave higher median ratings of the app as being helpful with NRT use $(P=0.02)$. Additionally, all intervention participants, 


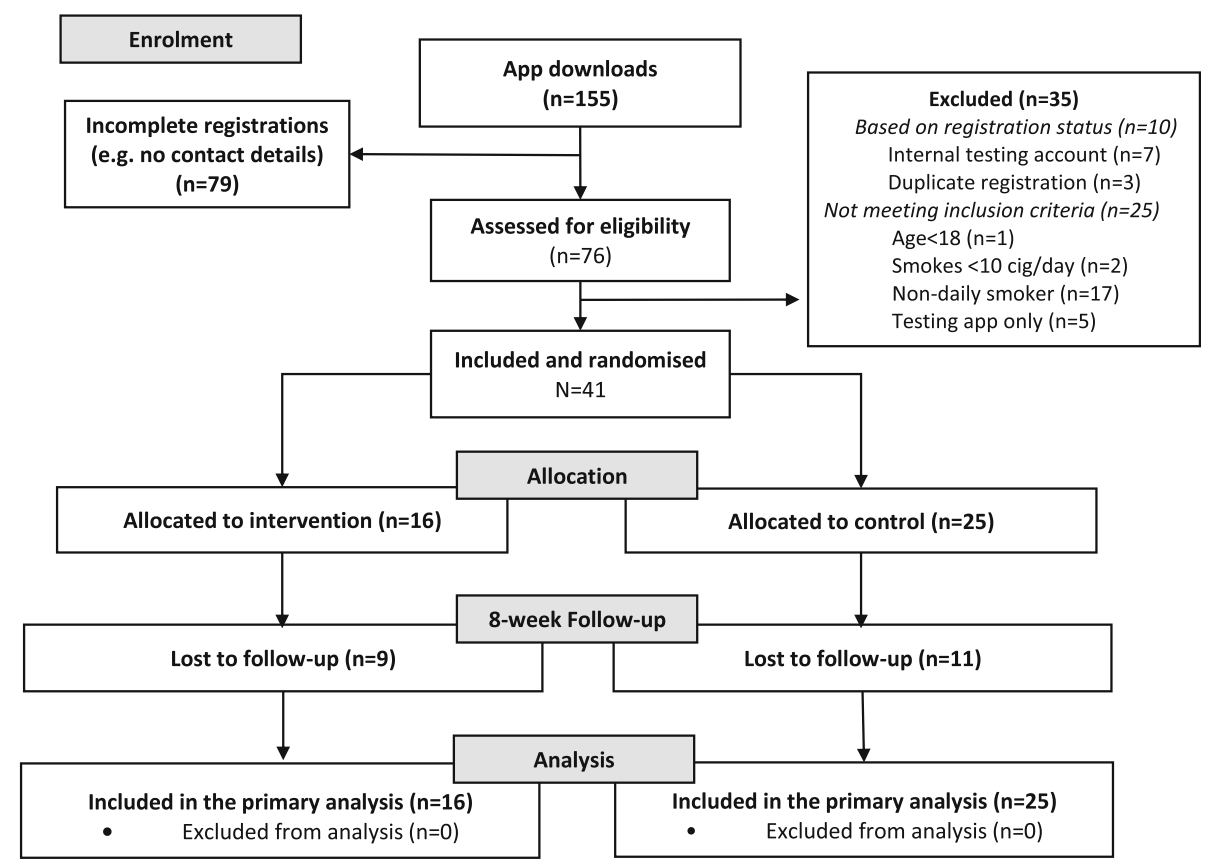

Fig. 1 Flowchart of participants in the NRT2Quit trial

compared with $28.6 \%$ among the control participants, stated that they would recommend the app to others $(P=0.01)$.

\section{Discussion}

\section{General summary}

Owing to very challenging recruitment through community pharmacies, the study was terminated with 41 participants. Nevertheless, it resulted in some important insights. First, the full app version (intervention) led to numerically greater self-reported $(25.0 \%$ versus $12.0 \%)$ and biochemically verified $(25.0 \%$ versus $8.0 \%)$ short-term quit rates, although the differences were not statistically significant when assessed using traditional statics ( $P$ values). The Bayes factors for the primary outcome suggest 'anecdotal' evidence that NRT2Quit could aid cessation but they demonstrate that that data were not sensitive to distinguish between experimental and null hypotheses, and more research is needed. Second, the intervention participants had statistically significant greater engagement and satisfaction with the app. On some indicators of NRT use (e.g., duration), there was an indication that intervention participants used more of it. Taken together, these findings suggest that the support offered by NRT2Quit app may aid cessation and warrants an adequately powered study, but establishing a feasible recruitment channel in the real world may be a major challenge.

The cessation rates reported in this study are similar to those found in other research, but biochemical verification of abstinence was rarely conducted in most other trials [8-10]. The findings suggesting greater effectiveness of the intervention version of the NRT2Quit app are all the more encouraging as the control app version already included several evidence-based BCTs that were shown to improve cessation, including goal setting and monitoring [39]. However, it must be acknowledged that since NRT2Quit was a complex intervention offering both generic support with smoking cessation and dedicated support with NRT use, the trial could not identify specific active ingredients that may be driving the effect. Owing to the small sample, it was also not possible to explore predictors of cessation.

In line with other findings from digital cessation interventions, attrition from the study was high and app engagement was relatively low, although the mean number of logins was in line with usage data from other digital interventions $[10,11,57]$. However, NRT2Quit offered access to the core content immediately following the registration and therefore it is possible that participants had accessed relevant advice already during their first visit, which might have been sufficient to optimise NRT use and improve cessation. The slow recruitment and high attrition could be at least partially explained by the lack of contact with the researchers at enrolment and lack of incentives at follow-up data (except as part of the saliva sample collection) [10].

\section{Low recruitment rate}

Despite securing access to more than 300 community pharmacies across the UK and extending the recruitment window, the study seriously under-recruited; only 
Table 1 Baseline characteristics of NRT2Quit trial participants

\begin{tabular}{|c|c|c|c|}
\hline & $\begin{array}{l}\text { Total } \\
(n=41)\end{array}$ & $\begin{array}{l}\text { Intervention } \\
(n=16)\end{array}$ & $\begin{array}{l}\text { Control } \\
(n=25) \\
\end{array}$ \\
\hline Female, \% (N) & $51.2(21)$ & $37.5(6)$ & $60.0(15)$ \\
\hline Age in years, mean (SD) & $33.4(10.02)$ & $32.1(9.07)$ & $34.3(10.67)$ \\
\hline Has post-16 years qualification, \% (N) & $51.2(21)$ & $56.3(9)$ & $48.0(12)$ \\
\hline CPD, mean (SD) & $18.7(6.54)$ & $17.9(5.39)$ & $19.2(7.24)$ \\
\hline Smokes within 5 min of waking up, \% (N) & $39.0(16)$ & $37.5(6)$ & $40.0(10)$ \\
\hline $\mathrm{HSI}$, mean (SD) & $3.2(1.32)$ & $3.3(1.24)$ & $3.2(1.39)$ \\
\hline \multicolumn{4}{|l|}{ When made a last quit attempt, \% (N) } \\
\hline Past 12 months & $48.8(20)$ & $68.8(11)$ & $36.0(9)$ \\
\hline$>12$ months ago & $39.0(16)$ & $18.8(3)$ & $52.0(13)$ \\
\hline Never & $12.2(5)$ & $12.5(2)$ & $12.0(3)$ \\
\hline \multicolumn{4}{|l|}{ How learned about the app, \% (N) } \\
\hline Pharmacy & $56.1(23)$ & $31.3(5)$ & $72.0(18)$ \\
\hline App store or Google search & $26.8(11)$ & $37.5(6)$ & $20.0(5)$ \\
\hline Other & $17.1(7)$ & $31.3(5)$ & $8.0(2)$ \\
\hline \multicolumn{4}{|l|}{ Used any cessation aids in the past ${ }^{\#}, \%(\mathrm{~N})$} \\
\hline No aids & $7.3(3)$ & $12.5(2)$ & $4.0(1)$ \\
\hline NRT & $41.5(17)$ & $62.5(10)$ & $28.0(7)$ \\
\hline Other medications & $12.2(5)$ & $0.0(0)$ & $20.0(5)$ \\
\hline Stop-smoking services & $9.8(4)$ & $16.0(4)$ & $0.0(0)$ \\
\hline Apps & $2.4(1)$ & $0.0(0)$ & $4.0(1)$ \\
\hline E-cigarettes & $24.4(10)$ & $18.8(3)$ & $28.0(7)$ \\
\hline Other & $2.4(1)$ & $2.4(1)$ & $0.0(0)$ \\
\hline \multicolumn{4}{|l|}{ Type of NRT used at baseline, \% (N) } \\
\hline Patch only & $29.3(12)$ & $37.5(6)$ & $24.0(6)$ \\
\hline Fast-acting NRT only & $43.9(18)$ & $37.5(6)$ & $48.0(12)$ \\
\hline Combination of patch and fast-acting NRT & $26.8(11)$ & $25.0(4)$ & $28.0(7)$ \\
\hline \multicolumn{4}{|l|}{ Reasons for selecting $\mathrm{NRT}^{\mathrm{a}}, \%(\mathrm{~N})$} \\
\hline Used it before & $40.0(16)$ & $50.0(8)$ & $33.3(8)$ \\
\hline Recommendations from an HCP & $15.0(6)$ & $18.8(3)$ & $12.5(3)$ \\
\hline Other, including wanting to try something new & $45.0(18)$ & $31.3(5)$ & $54.2(13)$ \\
\hline Obtained advice from HCPs on NRT use ${ }^{b}$ & $20.5(8)$ & $20.0(3)$ & $20.8(5)$ \\
\hline \multicolumn{4}{|l|}{ Method of obtaining $\mathrm{NRT}^{\mathrm{b}}, \%(\mathrm{~N})$} \\
\hline OTC only & $25.6(10)$ & $20.0(3)$ & $29.2(7)$ \\
\hline Rx only & $35.9(14)$ & $33.3(5)$ & $37.5(9)$ \\
\hline OTC and Rx & $38.5(15)$ & 46.7 (7) & 33.3 (8) \\
\hline
\end{tabular}

Abbreviations: CPD cigarettes per day, HCP healthcare professional, HSI heaviness of smoking index [22], $N$ number, NRT nicotine replacement therapy, OTC over the counter, $R x$ by prescription, $S D$ standard deviation.

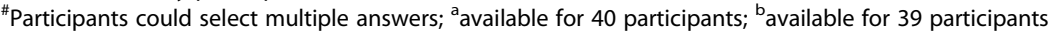

$4 \%$ of the target sample were enrolled. There could be several reasons for this. First, relying on recruitment via printed materials distributed in community pharmacies but with no researcher or HCP engagement proved infeasible. The site visits after the study initiation identified further challenges to recruitment in this context: (i) the leaflet displays were not sufficiently prominent; (ii) at pharmacies embedded within larger supermarkets, the OTC NRT was more prominently displayed on the general supermarket floors (managed by different managerial offices) rather than the pharmacy sections that supported the study; (iii) other cessation campaigns were run concurrently in the pharmacies; and (iv) lack of training and no direct involvement of the pharmacy staff might have 
Table 2 Cessation outcomes in NRT2Quit trial (smoking status in past 4 weeks assessed at 8-week follow-up)

\begin{tabular}{|c|c|c|c|c|c|c|c|}
\hline & Total $(n=41)$ & $\begin{array}{l}\text { Intervention } \\
(n=16)\end{array}$ & $\begin{array}{l}\text { Control } \\
(n=25)\end{array}$ & $P$ value* & OR $(95 \% \mathrm{Cl})$ & $\begin{array}{l}\text { Bayes factor }{ }^{a} \\
\text { uniform } \\
\text { (OR of } 1 \text { to } 3 \text { ) }\end{array}$ & $\begin{array}{l}\text { Bayes factor }^{a} \\
\text { half normal } \\
(\mathrm{OR}=1.2,1.7,2.5)\end{array}$ \\
\hline Primary cessation outcome (verified) & $\%(n)$ & $\%(n)$ & $\%(n)$ & & & & \\
\hline \multicolumn{8}{|l|}{ Smoking status $1 T^{1}$} \\
\hline Not smoking & $14.6(6)$ & $25.0(4)$ & $8.0(2)$ & 0.19 & $3.83(0.61-24.02)$ & 1.92 & $1.24,1.70,1.99$ \\
\hline Assumed to be smoking & $85.4(35)$ & $75.0(12)$ & $92.0(23)$ & & - & - & - \\
\hline Secondary outcome (self-reported) & & $\%(n)$ & & & & & \\
\hline \multicolumn{8}{|l|}{ Smoking status ITT } \\
\hline Not smoking & $17.1(7)$ & $25.0(4)$ & $12.0(3)$ & 0.40 & $2.44(0.47-12.78)$ & 1.52 & $1.18,1.41,1.43$ \\
\hline Assumed to be smoking & $82.9(34)$ & $75.0(12)$ & $88.0(22)$ & & - & - & - \\
\hline \multicolumn{8}{|l|}{ Smoking status ITT } \\
\hline Not smoking & $17.1(7)$ & $25.0(4)$ & $12.0(3)$ & 0.12 & - & - & - \\
\hline Smoking $<5$ cigarettes & $2.4(1)$ & $6.3(1)$ & $0.0(0)$ & & - & - & - \\
\hline Smoking $\geq 5$ cigarettes & $31.7(13)$ & $12.5(2)$ & $44.0(11)$ & & - & - & - \\
\hline Not contacted/assumed to be smoking & 488. (20) & $56.3(9)$ & $44.0(11)$ & & - & - & - \\
\hline
\end{tabular}

${ }^{1}$ Two subjects self-reporting not smoking had salivary cotinine of more than $100 \mathrm{ng} / \mathrm{mL}$ and anabasine levels of $0.2 \mathrm{ng} / \mathrm{mL}$. With a lower cutoff value for salivary anabasine level suggested recently by the processing lab $(<0.2 \mathrm{ng} / \mathrm{mL}), 18.8 \%$ of intervention and $4.0 \%$ of control participants met criteria for biochemical verification (odds ratio $(\mathrm{OR})=5.54,95 \%$ confidence interval $(\mathrm{Cl}) 0.52-58.76)$.

*For $2 \times 2$ analysis, the $P$ value reported is for Fisher's exact test; otherwise, for Pearson chi-squared.

${ }^{a}$ Bayes factor $<1 / 3$ suggests support for the null hypothesis, Bayes factor $>3$ suggests support for the experimental hypothesis, and intermediate values suggest that the data are insensitive (Dienes et al., [21], Brown et al., [12]).

Abbreviation: $1 \pi T$ intention to treat

resulted in the staff's not being effective or engaged in study promotion or insufficiently knowledgeable about the study and the app.

Second, potential participants might not have considered it as beneficial to access support with medication use, which could help explain the low interest to download NRT2Quit and join the trial. In a follow-up interview study [27] involving a new group of smokers and exsmokers who used NRT while quitting, it was found that while they viewed NRT2Quit as potentially beneficial, they reported many barriers in terms of limited capability, opportunity and low motivation to engage with any support and information about NRT use (e.g., leaflets, HCPs, and information on how to use the medications).

Third, NRT2Quit was available only on iOS devices and therefore a considerable proportion of smartphone users who have Android phones could not enrol. However, it is unlikely that developing an Android version of NRT2Quit would improve the recruitment. Research shows that iOS and Android users differ on a range of socio-demographic characteristics and on app use. For example, iOS users are more likely to download and use health apps and engage with more content $[13,58]$. iOS users also tend be better off financially [54] and thus might have more disposable income to purchase OTC NRT. On the other hand, given that lower socio-economic status is associated with higher smoking rates, future app developments should also include versions compatible with Android devices.
Fourth, recruiting participants into an online and remote trial such as this one required concealing the differences between the two app versions and prevented promoting the features and advice offered within the intervention app, thus likely leading to a less attractive offer in comparison with other commercially available apps to stop smoking. Finally, the trial took place during a phase marked by a decline in NRT popularity and an increase in the popularity of electronic cigarettes, which was reducing an already small pool of potential participants who use NRT to quit [6].

\section{Study limitations}

The response rate to the online survey was low, which limited the availability of data on NRT use and satisfaction. We were also unable to assess adherence to NRT in detail or account for changes to the patterns of use. Owing to the structure of the app database, it was also not possible to assess engagement with individual app components and fidelity of intervention delivery [37]. Additionally, the burden of joining the current trial was higher than that associated with accessing other cessation apps available on the market (e.g., it involved providing contact details and agreeing to follow-up procedures). It is likely that the recruited participants, as well as those who responded to the follow-up, were more motivated than the general population of smokers. Although this should not have impacted the main results (as motivation would have been similar in the control and intervention groups), 
Table 3 Secondary outcomes in NRT2Quit trial

\begin{tabular}{|c|c|c|c|c|}
\hline & Total $(n=41)$ & Intervention $(n=16)$ & Control $(n=25)$ & $P$ value $^{a}$ \\
\hline \multicolumn{5}{|l|}{ Follow-up status, \% (N) } \\
\hline Successfully contacted at 8 weeks, \% (N) & $51.2(21)$ & $43.8(7)$ & $56.0(14)$ & 0.53 \\
\hline \multicolumn{5}{|l|}{ Follow-up channel, \% (N) } \\
\hline Survey & $29.3(12)$ & $31.3(5)$ & $28.0(7)$ & \multirow[t]{3}{*}{$0.50^{b}$} \\
\hline Phone & $22.0(9)$ & $12.5(2)$ & $28.0(7)$ & \\
\hline Not contacted & $48.8(20)$ & $56.3(9)$ & $44.0(11)$ & \\
\hline Completed the survey on secondary outcomes, \% (N) & $29.3(12)$ & $31.3(5)$ & $28.0(7)$ & $1.00^{\mathrm{b}}$ \\
\hline Returned saliva samples when invited, \% (n/N) & $85.7(6 / 7)$ & $100.0(4 / 4)$ & $66.7(2 / 3)$ & 0.43 \\
\hline \multicolumn{5}{|l|}{ App usage after initial registration ${ }^{1}$} \\
\hline Logins, median (IQR) & $1.0(28.0)$ & $2.5(12.0)$ & $0(2.0)$ & $0.01^{*}$ \\
\hline Mean (SD) & $5.1(11.17)$ & $10.2(15.82)$ & $1.8(4.75)$ & $0.05^{c}$ \\
\hline \multicolumn{5}{|l|}{ Logins, \% (N) } \\
\hline 0 logins & $41.5(7)$ & $25.0(4)$ & $52.0(13)$ & \multirow[t]{4}{*}{$0.01^{\mathrm{d}^{*}}$} \\
\hline $1 \log$ in & $12.2(5)$ & $6.3(1)$ & $16.0(4)$ & \\
\hline $2-5$ logins & $31.7(13)$ & $3.7(6)$ & $28.0(7)$ & \\
\hline$\geq 6$ logins & $14.6(6)$ & $31.3(5)$ & $4.0(1)$ & \\
\hline Days logged in, median (IQR) & $1.0(10.0)$ & $1.5(5.0)$ & $0.0(1.0)$ & $0.03^{*}$ \\
\hline Mean (SD) & $2.7(5.98)$ & $5.1(8.35)$ & $1.2(3.18)$ & $0.10^{c}$ \\
\hline \multicolumn{5}{|l|}{ Days logged in, \% $(\mathrm{N})^{2}$} \\
\hline 0 days & $41.5(17)$ & $25.0(4)$ & $52.0(13)$ & \multirow[t]{4}{*}{$0.02^{\mathrm{d}^{*}}$} \\
\hline 1 day & $29.3(12)$ & $25.0(4)$ & $32.0(8)$ & \\
\hline 2-7 days & $19.5(8)$ & $31.3(5)$ & $12.0(3)$ & \\
\hline$\geq 8$ days & $9.8(4)$ & $18.8(3)$ & $4.0(1)$ & \\
\hline Follow-up survey responses ${ }^{3}$ & $(n=12)$ & $(n=5)$ & $(n=7)$ & \\
\hline \multicolumn{5}{|l|}{ NRT use and other cessation behaviour, \% (N) } \\
\hline Made a serious QA since registering & $91.7(11)$ & $100.0(5)$ & $85.7(6)$ & 1.00 \\
\hline Used additional cessation support & $83.3(10)$ & $60.0(3)$ & $100.0(7)$ & 0.15 \\
\hline Used NRT in past 8 weeks & $83.3(10)$ & $80.0(4)$ & $85.7(6)$ & 1.00 \\
\hline Used NRT on the day of follow-up & $58.3(7)$ & $100.0(5)$ & $28.6(2)$ & $0.03^{*}$ \\
\hline Used NRT for $\geq 5$ weeks & $66.7(8)$ & $100.0(5)$ & $42.9(3)$ & 0.08 \\
\hline Used NRT every day in weeks when NRT used & $58.3(7)$ & $40.0(2)$ & $71.4(5)$ & 0.56 \\
\hline \multicolumn{5}{|l|}{ App satisfaction } \\
\hline App helpful for quitting $(1-5)^{\#}$, median (IQR) & $3.0(1.0)$ & $3.0(1.0)$ & $2.0(2.0)$ & 0.07 \\
\hline App helpful for quitting (1-5)\# Mean (SD) & $2.6(.90)$ & $3.2(.45)$ & $2.14(.90)$ & $0.04^{4^{*}}$ \\
\hline App helpful for NRT use $(1-5)^{\#}$, median (IQR) & $3.0(3.0)$ & $4.0(1.0)$ & $2.0(2.0)$ & $0.02^{*}$ \\
\hline App helpful for NRT use (1-5)\#, Mean (SD) & $2.7(1.15)$ & $3.6(.55)$ & $2.0(1.00)$ & $0.01^{*}$ \\
\hline Recommend to others, \% (N) & $58.3(7)$ & $100.0(5)$ & $28.6(2)$ & $0.01^{*}$ \\
\hline
\end{tabular}

${ }^{1}$ : App usage includes data from any new sessions after registration was completed and excludes the time of registration and initial app exploration following the registration; data on usage and logins may be an underestimation as app use during offline use would not synchronise with the study database if the participants did not access the app online on any future occasion; ${ }^{2}$ : not consecutive days; ${ }^{3}$ : data assessed via online survey among 12 respondents; ${ }^{\#} 1=$ not at all, 5 = extremely

${ }^{a}$ Fisher's exact test for $2 \times 2$ and chi-squared for other categorical variables; ${ }^{\text {b }}$ owing to small sample size, a considerable proportion of cells in chi-squared analyses had expected count of less than 5; ' unequal variance; ${ }^{\mathrm{d}}$ linear-by-linear association; ${ }^{*}$ significant at $p<0.05$

Abbreviations: IQR interquartile range, $N$ number, NRT nicotine replacement therapy, QA quit attempt, SD standard deviation 
the findings should be interpreted with caution and their generalisability is limited.

Another limitation is that, if the app did improve quit rates, we cannot be sure that this was through improved NRT adherence. It is possible that it was through more general support for quitting. The sample size was too small to conduct meaningful mediation analysis involving NRT adherence.

\section{Study strengths}

We collected contact details through the app and followed up participants outside of the app and we conducted biochemical validation of self-reported abstinence, which had a good response rate and which was not carried out in other studies (e.g., $[8,60])$. The study also enabled us to make important methodological observations about recruitment and engagement of smokers with smartphone-based support for NRT use. Finally, we evaluated the app in a setting that had higher ecological validity than earlier studies, namely one involving no contact with the researchers at enrolment or incentives for app engagement and surveybased follow-up, some of which have been used in other studies $[9,10,14]$.

\section{Future directions}

The findings warrant further development of NRT2Quit and a well-powered study. However, it will be necessary to establish better recruitment channels and methods for such a trial, which in the case of community pharmacies may require engaging the pharmacy staff in active recruitment into the trial and possibly offering incentives [16]. Additionally, it would be relevant to evaluate NRT2Quit as part of face-to-face support to establish whether the app could augment cessation and medication use in this context. Moreover, it is possible that actively promoting the benefits of the full NRT2Quit and offering only this version would lead to better uptake among the smokers. Thus, assessing NRT2Quit in a study with a waitlist control or in an observational study is a possible future direction, especially if the recruitment relies on campaigns in social media.

\section{Conclusions}

In a limited evaluation disrupted by extremely poor recruitment, there was inconclusive evidence that the NRTN2Quit smoking cessation app may impact on short-term quit rates and some preliminary evidence that it may impact on medication use, app use, and satisfaction but this would need to be confirmed in definitive studies. Future research will need to implement more effective recruitment strategies.

\section{Additional files}

Additional file 1: CONSORT (Consolidated Standards of Reporting Trials) 2010 checklist of information to include when reporting a randomised trial. (DOCX $41 \mathrm{~kb}$ )

Additional file 2: Changes to protocol and rationale. (DOCX 18 kb)

Additional file 3: Recruitment materials. (DOCX 514 kb)

Additional file 4: Functionality and screenshots of NRT2Quit (intervention and control). (DOCX 647 kb)

Additional file 5: Flow of participants through the NRT2Quit app and the trial. (DOCX $189 \mathrm{~kb}$ )

\section{Abbreviations}

app: Application; BCT: Behaviour change technique; CONSORT: Consolidated Standards of Reporting Trials; HCP: Healthcare professional; ITT: Intention-totreat; NRT: Nicotine replacement therapy; OR: Odds ratio; OTC: Over the counter

\section{Acknowledgements}

We would like to express our gratitude to the managerial and communications teams at ASDA, Well Pharmacy and Superdrug for agreeing to support recruitment for the study and to PHE for establishing initial contacts with ASDA We are grateful to all pharmacy staff and independent pharmacies in London and the rest of the UK who promoted the study among their customers. We are grateful to Andy McEwen, director of the National Centre for Smoking Cessation and Training (NCSCT), for his invaluable advice and guidance on smoking cessation and NRT use as well as feedback on the NRT2Quit prototype. We would like to thank the NCSCT for offering administrative support for the project. We would like to thank everyone who has contributed to finalizing the app through user testing and making comments to the early prototypes. The team is part of the UK Centre for Tobacco \& Alcohol Studies and University College London Tobacco and Alcohol Research Group.

\section{Authors' contributions}

TR prepared the initial trial protocol and obtained the funding. $\mathrm{AH}, \mathrm{JB}$ and RW contributed to revising and finalizing the final trial design. $\mathrm{AH}$ has conducted formative research that informed NRT2Quit development, guided the work of IT teams that developed the NRT2Quit app and has lead on all aspect of the trial, including setting up, data collection and analysis, in consultation with JB, RW, LS and TR. AH drafted the first version of the manuscript. JB, LS, RW and TR revised the manuscript. All authors approved the final version of the manuscript.

\section{Funding}

The cost of developing NRT2Quit and conducting the trial was covered by a 2013 Global Research Award in Nicotine Dependence (GRAND) received by TR (principal investigator). AH was funded by a 4-year British Heart Foundation PhD studentship at University College London (FS/13/59/30649) and partially by GRAND. JB's salary was funded by a programme grant from Cancer Research UK (C1417/A22962). RW's salary was funded by Cancer Research UK for part of the preparation of this manuscript. TR's salary was funded by GRAND. The funders had no influence over the study design, data collection, analysis, interpretation of the data, preparation of the manuscript or the decision to submit it.

\section{Availability of data and materials}

The datasets used or analysed (or both) during this study are available from the corresponding author on reasonable request.

Ethics approval and consent to participate

The study received ethical approval from the University College London Research Ethics Committee (ID: 5398/001). All participants provided informed consent before participating.

Consent for publication

Not applicable.

\section{Competing interests}

$\mathrm{AH}$ led the development of the NRT2Quit app and the NRT2Quit trial as part of her PhD funded by British Heart Foundation 4-year PhD at University 
College London, has conducted administrative tasks for the NRT2Quit trial in a paid capacity from GRAND, and has received unrestricted funds as part of a project Global Bridges at Mayo Clinic and Pfizer Independent Grants for Learning and Change Request for Proposals: EUROPEAN PROGRAM. LS has received honoraria for talks, an unrestricted research grant and travel expenses to attend meetings and workshops from Pfizer and Johnson \& Johnson and has acted as a paid reviewer for grant-awarding bodies and as a paid consultant for healthcare companies. Other research has been funded by the government, a community-interested company (National Centre for Smoking Cessation) and charitable sources. JB received unrestricted research grants to study smoking cessation from Pfizer who manufacture smoking cessation medications. RW undertakes research and consultancy and receives fees for speaking from companies that develop and manufacture smoking cessation medications (Pfizer, Johnson \& Johnson, GlaxoSmithKline). JB and RW are both unpaid members of the scientific steering group of the Smoke Free mobile application. TR has received honoraria from Pfizer, Novartis, GlaxoSmithKline, AstraZeneca and Roche as a speaker in activities related to continuing medical education. He has also received financial support for investigator-initiated trials from Pfizer and Johnson \& Johnson. The views presented are not necessarily the views of the funders.

\section{Author details}

${ }^{1}$ Clinical, Educational and Health Psychology, University College London, 1-19 Torrington Place, WC1E 6BT, London, UK. ${ }^{2}$ Behavioural Science and Health, University College London, 1-19 Torrington Place, WC1E 6BT, London, UK. ${ }^{3}$ Centre for Behaviour Change, University College London, Room 353, 1-19 Torrington Place, London WC1E 6BT, UK. ${ }^{4}$ National Centre for Smoking Cessation and Training, 1 Great Western Industrial Centre, Dorchester DT1 1RD, UK. ${ }^{5}$ Clinic for Cardiology and Pneumology, University Medical Centre, Universitaetsmedizin Goettingen UBFT, Robert-Koch, Strasse 40, 37075 Goettingen, Germany.

\section{Received: 25 February 2019 Accepted: 9 August 2019} Published online: 02 September 2019

\section{References}

1. Abroms LC, Padmanabhan N, Thaweethai L, Phillips T. iPhone apps for smoking cessation: a content analysis. Am J Prev Med. 2011;40:279-85. https://doi.org/10.1016/j.amepre.2010.10.032.

2. Ahmed I, Ahmad NS, Ali S, Ali S, George A, Saleem Danish H, et al. Medication Adherence Apps: Review and Content Analysis. JMIR Mhealth Uhealth. 2018;6:e62. https://doi.org/10.2196/mhealth.6432.

3. Apollonio D, Glantz SA. Tobacco industry research on nicotine replacement therapy: "If anyone is going to take away our business it should be us". Am J Public Health. 2017:e1-7. https://doi.org/10.2105/AJPH.2017.303935.

4. Atkins L, Francis J, Islam R, O'Connor D, Patey A, Ivers N, et al. A guide to using the Theoretical Domains Framework of behaviour change to investigate implementation problems. Implement Sci. 2017;12:77. https://doi.org/10.1186/s13012-017-0605-9.

5. Beard E, Bruguera C, McNeill A, Brown J, West R. Association of amount and duration of NRT use in smokers with cigarette consumption and motivation to stop smoking: a national survey of smokers in England. Addict Behav. 2015;40:33-8. https://doi.org/10.1016/j.addbeh.2014.08.008.

6. Beard E, West R, Michie S, Brown J. Association between electronic cigarette use and changes in quit attempts, success of quit attempts, use of smoking cessation pharmacotherapy, and use of stop smoking services in England: time series analysis of population trends. BMJ. 2016;354:i4645. https://doi.org/10.1136/bmj.i4645.

7. SRNT Subcommittee on Biochemical Verification. Biochemical verification of tobacco use and cessation. Nicotine Tob Res. 2002;4:149-159. doi: https://doi.org/10.1080/14622200210123581.

8. BinDhim NF, McGeechan K, Trevena L. Smartphone Smoking Cessation Application (SSC App) trial: a multicountry double-blind automated randomised controlled trial of a smoking cessation decision-aid 'app'. BMJ Open. 2018;8:e017105. https://doi.org/10.1136/bmjopen-2017-017105.

9. Bricker JB, Copeland W, Mull KE, Zeng EY, Watson NL, Akioka KJ, et al. Single-arm trial of the second version of an acceptance \& commitment therapy smartphone application for smoking cessation. Drug Alcohol Depend. 2017;170:37-42. https://doi.org/10.1016/j.drugalcdep.2016.10.029.

10. Bricker JB, Mull KE, Kientz JA, Vilardaga R, Mercer LD, Akioka KJ, et al. Randomized, controlled pilot trial of a smartphone app for smoking cessation using acceptance and commitment therapy. Drug Alcohol Depend. 2014;143:87-94. https://doi.org/10.1016/j.drugalcdep.2014.07.006.

11. Brown J, Michie S, Geraghty AWA, Yardley L, Gardner B, Shahab L, et al. Internet-based intervention for smoking cessation (StopAdvisor) in people with low and high socioeconomic status: a randomised controlled trial. Lancet Respir Med. 2014;2:997-1006. https://doi.org/10.1016/s2213-2600(14)70195-x.

12. Brown J, Michie S, Walmsley M, West R. An Online Documentary Film to Motivate Quit Attempts Among Smokers in the General Population (4Weeks2Freedom): A Randomized Controlled Trial. Nicotine Tob Res. 2016; 18:1093-100. https://doi.org/10.1093/ntr/ntv161.

13. BuildFire. Android vs. iOS Users: How Do They Behave Differently?, 2017 from https://buildfire.com/ios-android-users/. Accessed 14 Dec 2018. (Archived by WebCite ${ }^{\oplus}$ at http://www.webcitation.org/74fbiq8jE).

14. Buller DB, Borland R, Bettinghaus EP, Shane JH, Zimmerman DE. Randomized trial of a smartphone mobile application compared to text messaging to support smoking cessation. Telemed J E Health. 2014;20:206-14. https://doi.org/10.1089/tmj.2013.0169.

15. Carpenter MJ, Ford ME, Cartmell K, Alberg AJ. Misperceptions of Nicotine Replacement Therapy Within Racially and Ethnically Diverse Smokers. J Natl Med Assoc. 2011;103:885-96. https://doi.org/10.1016/s0027-9684(15)30444-2.

16. Corelli RL, Zillich AJ, de Moor C, Giuliano MR, Arnold J, Fenlon CM, et al. Recruitment of community pharmacies in a randomized trial to generate patient referrals to the tobacco quitline. Res Social Adm Pharm. 2013;9:396-404. https://doi.org/10.1016/j.sapharm.2012.06.001.

17. Cramer JA, Roy A, Burrell A, Fairchild CJ, Fuldeore MJ, Ollendorf DA, et al. Medication compliance and persistence: terminology and definitions. Value Health. 2008;11:44-7. https://doi.org/10.1111/j.1524-4733.2007.00213.x.

18. Cropsey KL, Hendricks PS, Schiavon S, Sellers A, Froelich M, Shelton RC, et al. A pilot trial of In vivo NRT sampling to increase medication adherence in community corrections smokers. Addict Behav. 2017;67:92-9. https://doi. org/10.1016/j.addbeh.2016.12.011.

19. Curry SJ, Ludman EJ, McClure J. Self-administered treatment for smoking cessation. J Clin Psychol. 2003;59:305-19. https://doi.org/10.1002/jclp.10131.

20. Dienes Z. Understanding Psychology as a Science: An Introduction to Scientific and Statistical Inference. Basingstoke: Palgrave Macmillan; 2008.

21. Dienes Z. Using Bayes to get the most out of non-significant results. Front Psychol. 2014:5:781. https://doi.org/10.3389/fpsyg.2014.00781.

22. Etter JF, Duc TV, Perneger TV. Validity of the Fagerstrom test for nicotine dependence and of the Heaviness of Smoking Index among relatively light smokers. Addiction. 1999;94:269-81.

23. Eysenbach G. The law of attrition. J Med Internet Res. 2005;7:e11. https://doi.org/10.2196/jmir.7.1.e11.

24. Eysenbach G, CONSORT-EHEALTH Group. CONSORT-EHEALTH: improving and standardizing evaluation reports of Web-based and mobile health interventions. J Med Internet Res. 2011;13:e126. https://doi.org/10.2196/ jmir.1923.

25. US Food and Drug Adminstration. Mobile Medical Applications. 2018 from https://www.fda.gov/medicaldevices/digitalhealth/ mobilemedicalapplications/default.htm. Accessed 14 Dec 2018. (Archived by WebCite $^{\oplus}$ at http://www.webcitation.org/74feT3w0D).

26. Herbec A, Beard E, Brown J, Gardner B, Tombor I, West R. The needs and preferences of pregnant smokers regarding tailored Internet-based smoking cessation interventions: a qualitative interview study. BMC Public Health. 2014;14:1070. https://doi.org/10.1186/1471-2458-14-1070.

27. Herbec A, Tombor I, Shahab L, West R. "If I'd known..." - a theory-informed systematic analysis of missed opportunities in optimising use of nicotine replacement therapy and accessing relevant support: A qualitative study. Int J Behav Med. 2018;25:579-91. https://doi.org/10.1007/s12529-018-9735-y.

28. Higgins JP. Smartphone Applications for Patients' Health and Fitness. Am J Med. 2016;129:11-9. https://doi.org/10.1016/j.amjmed.2015.05.038.

29. Hoeppner BB, Hoeppner SS, Seaboyer L, Schick MR, Wu GW, Bergman BG, et al. How Smart are Smartphone Apps for Smoking Cessation? A Content Analysis. Nicotine Tob Res. 2016;18:1025-31. https://doi.org/10.1093/ntr/ntv117.

30. Horne R, Chapman SC, Parham R, Freemantle N, Forbes A, Cooper V. Understanding patients' adherence-related beliefs about medicines prescribed for long-term conditions: a meta-analytic review of the Necessity-Concerns Framework. PLoS One. 2013;8:e80633. https://doi.org/1 0.1371/journal.pone.0080633.

31. Hughes JR, Fanshawe TR, Stead LF. Is nicotine replacement really ineffective? A reply to Stanley and Massey. J Clin Epidemiol. 2017:81:143-4. https://doi.org/10.1016/j.jclinepi.2016.08.013. 
32. Jackson C, Eliasson L, Barber N, Weinman J. Applying COM-B to medication adherence: a suggested framework for research and interventions. Eur Health Psychol. 2014;16:7-17.

33. Kasza KA, Hyland AJ, Borland R, McNeill AD, Bansal-Travers M, Fix BV, et al. Effectiveness of stop-smoking medications: findings from the International Tobacco Control (ITC) Four Country Survey. Addiction. 2013;108:193-202. https://doi.org/10.1111/j.1360-0443.2012.04009.x.

34. Kotz D, Brown J, West R. Prospective cohort study of the effectiveness of smoking cessation treatments used in the "real world". Mayo Clin Proc. 2014;89:1360-7. https://doi.org/10.1016/j.mayocp.2014.07.004.

35. Kotz D, Brown J, West R. 'Real-world' effectiveness of smoking cessation treatments: a population study. Addiction. 2014;109:491-9. https://doi.org/1 0.1111 /add.12429.

36. Kotz D, Fidler J, West R. Factors associated with the use of aids to cessation in English smokers. Addiction. 2009:104:1403-10. https://doi.org/10.1111/ j.1360-0443.2009.02639.x

37. Kruse GR, Rigotti NA, Raw M, McNeill A, Murray R, Pine-Abata H, et al. Content and Methods used to Train Tobacco Cessation Treatment Providers: An International Survey. J Smok Cessat. 2017;12:213-20. https://doi.org/10.1017/jsc.2016.22.

38. Lehane E, McCarthy G. Intentional and unintentional medication nonadherence: a comprehensive framework for clinical research and practice? A discussion paper. Int J Nurs Stud. 2007:44:1468-77. https://doi.org/10.1016/j. ijnurstu.2006.07.010.

39. Lorencatto F, West R, Michie S. Specifying evidence-based behavior change techniques to aid smoking cessation in pregnancy. Nicotine Tob Res. 2012; 14:1019-26. https://doi.org/10.1093/ntr/ntr324

40. Ma P, Kendzor DE, Poonawalla IB, Balis DS, Businelle MS. Daily nicotine patch wear time predicts smoking abstinence in socioeconomically disadvantaged adults: An analysis of ecological momentary assessment data. Drug Alcohol Depend. 2016;169:64-7. https://doi.org/10.1016/j. drugalcdep.2016.10.013.

41. Michie S, Atkins L, West R. The Behaviour Change Wheel: A guide to designing interventions. 1st ed. London: Silverback Publishing; 2014

42. Michie S, Richardson M, Johnston M, Abraham C, Francis J, Hardeman W, et al. The behavior change technique taxonomy (v1) of 93 hierarchically clustered techniques: building an international consensus for the reporting of behavior change interventions. Ann Behav Med. 2013:46:81-95. https://doi.org/10.1007/s12160-013-9486-6.

43. Michie $S$, van Stralen MM, West R. The behaviour change wheel: a new method for characterising and designing behaviour change interventions. Implement Sci. 2011;6:42. https://doi.org/10.1186/1748-5908-6-42.

44. Michie S, West W. A Guide to Development and Evaluation of Digital Behaviour Change Interventions in Healthcare. London: Silverback Publishing; 2016.

45. Morrissey EC, Corbett TK, Walsh JC, Molloy GJ. Behavior Change Techniques in Apps for Medication Adherence: A Content Analysis. Am J Prev Med. 2016;50:e143-6. https://doi.org/10.1016/j.amepre.2015.09.034.

46. Pacek LR, McClernon FJ, Bosworth HB. Adherence to pharmacological smoking cessation interventions: A literature review and synthesis of correlates and barriers. Nicotine Tob Res. 2018;20:1163-72. https://doi.org/1 $0.1093 / n t r / n t x 210$

47. Pulverman R, Yellowlees PM. Smart devices and a future of hybrid tobacco cessation programs. Telemed J E Health. 2014;20:241-5. https://doi.org/10.1 089/tmj.2013.0096.

48. Raupach T, Brown J, Herbec A, Brose L, West R. A systematic review of studies assessing the association between adherence to smoking cessation medication and treatment success. Addiction. 2014;109:35-43. https://doi. org/10.1111/add.12319.

49. Raupach T, West R, Brown J. The most "successful" method for failing to quit smoking is unassisted cessation. Nicotine Tob Res. 2013;15:748-9. https://doi.org/10.1093/ntr/nts164.

50. Rigotti NA, Chang Y, Rosenfeld LC, Japuntich SJ, Park ER, Tindle HA, et al Interactive Voice Response Calls to Promote Smoking Cessation after Hospital Discharge: Pooled Analysis of Two Randomized Clinical Trials. J Gen Intern Med. 2017;32:1005-13. https://doi.org/10.1007/s11606-017-4085-z.

51. Ruano-Ravina A, Figueiras A, Montes-Martinez A, Barros-Dios JM. Dose-response relationship between tobacco and lung cancer: new findings. Eur J Cancer Prev. 2003;12:257-63. https://doi.org/10.1097/01.cej.0000082609.46998.a2.

52. Santo K, Richtering SS, Chalmers J, Thiagalingam A, Chow CK, Redfern J. Mobile Phone Apps to Improve Medication Adherence: A Systematic
Stepwise Process to Identify High-Quality Apps. JMIR Mhealth Uhealth. 2016; 4:e132. https://doi.org/10.2196/mhealth.6742.

53. Schlam TR, Cook JW, Baker TB, Hayes-Birchler T, Bolt DM, Smith SS, et al. Can we increase smokers' adherence to nicotine replacement therapy and does this help them quit? Psychopharmacology (Berl.). 2018;235:2065-75. https://doi.org/10.1007/s00213-018-4903-y.

54. Schonfeld E. Androids Are For Cheap Pessimists, iPhones Are For Worldly Optimists. 2011 from https://techcrunch.com/2011/08/15/androidspessimists-iphones-optimists/. Accessed 14 June 2018.

55. Stanley TD, Massey S. Evidence of nicotine replacement's effectiveness dissolves when meta-regression accommodates multiple sources of bias. J Clin Epidemiol. 2016;79:41-5. https://doi.org/10.1016/j.jclinepi.2016.03.024.

56. Stead LF, Perera R, Bullen C, Mant D, Hartmann-Boyce J, Cahill K, et al. Nicotine replacement therapy for smoking cessation. Cochrane Database Syst Rev. 2012; 11:CD000146. https://doi.org/10.1002/14651858.CD000146.pub4

57. Taylor GMJ, Dalili MN, Semwal M, Civljak M, Sheikh A, Car J. Internet-based interventions for smoking cessation. Cochrane Database Syst Rev. 2017;9: CD007078. https://doi.org/10.1002/14651858.CD007078.pub5.

58. Ubhi HK, Kotz D, Michie S, van Schayck OCP, West R. A comparison of the characteristics of IOS and Android users of a smoking cessation app. Transl Behav Med. 2017;7:166-71. https://doi.org/10.1007/s13142-016-0455-z.

59. Ubhi HK, Michie S, Kotz D, van Schayck OC, Selladurai A, West R. Characterising smoking cessation smartphone applications in terms of behaviour change techniques, engagement and ease-of-use features. Trans Behav Med. 2016;6:410-7. https://doi.org/10.1007/s13142-015-0352-x.

60. Ubhi HK, Michie S, Kotz D, Wong WC, West R. A mobile app to aid smoking cessation: preliminary evaluation of SmokeFree28. J Med Internet Res. 2015; 17:e17. https://doi.org/10.2196/jmir.3479.

61. West R. The clinical significance of "small" effects of smoking cessation treatments. Addiction. 2007;102:506-9. https://doi.org/10.1111/j.1360-0443.2 007.01750.x

62. West R. The PRIME Theory of motivation as a possible foundation for addiction treatment. In: Drug Addiction Treatment in the 21st Century: Science and Policy Issues. Baltimore: Johns Hopkins University Press; 2007.

63. West R. Using Bayesian analysis for hypothesis testing in addiction science. Addiction. 2016;111:3-4. https://doi.org/10.1111/add.13053.

64. West R, Hajek P, Stead L, Stapleton J. Outcome criteria in smoking cessation trials: proposal for a common standard. Addiction. 2005;100:299-303. https://doi.org/10.1111/j.1360-0443.2004.00995.x.

\section{Publisher's Note}

Springer Nature remains neutral with regard to jurisdictional claims in published maps and institutional affiliations.

Ready to submit your research? Choose BMC and benefit from:

- fast, convenient online submission

- thorough peer review by experienced researchers in your field

- rapid publication on acceptance

- support for research data, including large and complex data types

- gold Open Access which fosters wider collaboration and increased citations

- maximum visibility for your research: over $100 \mathrm{M}$ website views per year

At $\mathrm{BMC}$, research is always in progress.

Learn more biomedcentral.com/submissions 